\title{
RUANG PERTUNJUKAN SENI DI BLOK M
}

\author{
Gary Cantonna Tamin ${ }^{1)}$, Petrus Rudi Kasimun ${ }^{2)}$
}

1) Program Studi S1 Arsitektur, Fakultas Teknik, Universitas Tarumanagara, garycantona@hotmail.com

2) Program Studi S1 Arsitektur, Fakultas Teknik, Universitas Tarumanagara, rudi.kasimun@gmail.com

\begin{abstract}
Abstrak
Seiring perkembangannya zaman, masyarakat khususnya di perkotaan cenderung memiliki sifat yang individualis dikarenakan rutinitas sehari-hari yang padat. Dimana sebagian besar waktu dihabiskan di tempat kerja, rumah ataupun pusat perbelanjaan. Manusia sebagai makhluk sosial yang seharusnya bersosialisasi dan berinteraksi dengan sesama untuk memenuhi kebutuhan sosial. Untuk memenuhi kebutuhan sosial di era modern saat ini, dibutuhkan wadah sosial yang dapat menampung aktivitas-aktivitas masyarakat sekitar. Sehingga masyarakat dapat saling bertemu, bersosialisasi dan juga berinteraksi melalui media wadah sosial tersebut. Jakarta Selatan, tepatnya di kawasan Blok M, dikenal sebagai tempat perkumpulan anak-anak muda pada zamannya. Namun, pada saat ini Blok M mulai ditinggalkan oleh masyarakat dikarenakan kawasan-kawasan lain mempunyai tempat berkumpul yang lebih memadai. Blok $\mathrm{M}$ merupakan kawasan yang memiliki banyak sekali komunitas seni, seperti pengamen jalanan, komunitas Jepang, musik kontemporer dan masih banyak lagi. Menurut Richard Florida, orang-orang kreatif mempunyai keinginan untuk melakukan hal-hal yang kreatif dan juga berkumpul dengan orang-orang kreatif lainnya. Hal ini mempunyai kesinambungan dimana The Third place menurut Ray Oldenburg, merupakan sebuah tempat dimana orang-orang dapat berkumpul dan saling berinteraksi untuk memenuhi kebutuhan sosial mereka. Blok $\mathrm{M}$ merupakan kawasan yang memiliki banyak sekali komunitas seni, seperti pengamen jalanan, komunitas Jepang, musik kontemporer dan masih banyak lagi. Ruang Pertunjukan Seni Blok M hadir sebagai ruang ketiga atau "The Third place" dan juga sebagai tempat untuk menunjukan dan mengasah kreatifitas, dimana masyarakat dapat berkumpul, berinteraksi dan beraktivitas dengan sesamanya.Proyek ini juga ditujukan sebagai wadah bagi komunitas-komunitas sekitar untuk berinteraksi dengan komunitas lainnya dan juga dapat menunjukan karyakarya mereka ke masyarakat luas, sehingga terjadi hubungan timbal balik antara masyarakat dengan komunitas setempat. Tidak menutup kemungkinan juga memicu timbulnya kolaborasi antara komunitas-komunitas tersebut, sehingga memunculkan sebuah karya pertunjukan seni kolaborasi yang baru dan unik.
\end{abstract}

\section{Kata kunci: komunitas seni; ruang ketiga; pertunjukan seni}

\begin{abstract}
As time goes by, people, especially in urban areas, tend to have individualistic characteristics due to their busy daily routines. Where most of the time spent at work, home or shopping centers. Humans as social creatures who should socialize and interact with others to meet social needs. To meet social needs in the current modern era, it takes a social container that can accommodate the activities of the surrounding community. So that people can meet with each other, socialize and also interact through these social media platforms. South Jakarta, precisely in the Blok M area, was known as a place for the gathering of young people of its time. However, at this time Blok $M$ has begun to be abandoned by the community because other regions have more adequate gathering places. Blok $M$ is an area that has a lot of art communities, such as street buskers, Japanese communities, contemporary music and much more. According to Richard Florida, creative people have the desire to do creative things and also get together with other creative people. This has a continuity where The Third place according to Ray Oldenburg, is a place where people can gather and interact with one another to meet their social needs. Blok $M$ is an area that has a lot of art communities, such as street buskers, Japanese
\end{abstract}


communities, contemporary music and much more. Blok M Performing Arts Space is present as the third space or "The Third place" and also as a place to show and hone creativity, where people can gather, interact and move with each other. This project is also intended as a forum for surrounding communities to interact with other communities and also can show their works to the wider community, so there is a reciprocal relationship between the community and the local community. Did not rule out the possibility of also triggering collaboration between these communities, thus bringing up a new and unique collaborative performing arts performance.

Keywords: art community; the third place; performing arts

\section{PENDAHULUAN}

\section{Latar Belakang}

Seiring perkembangannya zaman, masyarakat khususnya di perkotaan cenderung memiliki sifat yang individualis dikarenakan rutinitas sehari-hari yang padat. Dimana sebagian besar waktu mereka dihabiskan di tempat kerja, rumah ataupun pusat perbelanjaan. Manusia sebagai makhluk sosial yang seharusnya bersosialisasi dan berinteraksi dengan sesama untuk memenuhi kebutuhan sosial.

Untuk memenuhi kebutuhan sosial di era modern saat ini, dibutuhkan wadah sosial yang dapat menampung aktivitas-aktivitas masyarakat sekitar. Sehingga masyarakat dapat saling bertemu, bersosialisasi dan juga berinteraksi melalui media wadah sosial tersebut.

Blok $\mathrm{M}$ merupakan kawasan yang dijadikan tempat untuk berkumpul bagi anak-anak muda pada tahun 90-an, khususnya di daerah Melawai yang juga dikelilingi oleh 3 pusat perbelanjaan. Blok $M$ juga memiliki banyak sekali komunitas seni, seperti pengamenpengamen jalanan, komunitas Jepang, musik kontemporer dan masih banyak lagi. Namun, seiring berjalannya waktu, Blok $\mathrm{M}$ mulai ditinggalkan oleh masyarakat dikarenakan oleh pembangunan Moda Raya Terpadu yang membuat pencapaian ke Blok $\mathrm{M}$ menjadi sulit dan juga kawasan-kawasan lain yang jauh lebih cepat perkembangannya, sehingga banyak masyarakat yang lebih memilih untuk ke kawasan yang lain.

Hal-hal ini juga ditandai dengan penutupan sejumlah toko, pusat perbelanjaan dan aktivitas-aktivitas yang mulai menghilang. Komunitas-komunitas sekitar pun juga ikut terkena dampaknya, mereka mulai kehilangan tempat untuk berkumpul dan mempertunjukan karyakarya mereka. Maka dari itu, dibutuhkan sebuah tempat yang mewadahi kegiatan komunitas serta masyarakat dan juga dapat menarik para pengunjung dari luar Blok $\mathrm{M}$ untuk datang, sehingga terjadi sebuah interaksi antar masyarakat yang dapat memicu perkembangan kawasan Blok $\mathrm{M}$ itu sendiri.

\section{Rumusan Masalah}

Rumusan masalah yang timbul dari proyek ini adalah bagaimana proyek Ruang Pertunjukan Seni ini dapat menjadi "The Third place" bagi masyarakat di Blok M dan bagaimana caranya proyek Ruang Pertunjukan Seni ini dapat memicu timbulnya kolaborasi pertunjukanpertunjukan seni yang baru antara komunitas?

\section{Batasan Masalah}

Ruang lingkup dalam penulisan ini untuk menentukan fokus pada tema dan permasalahan,dimana para pengguna Blok $\mathrm{M}$ sebagai variabel tetap dan subyek yang diamati. Pengamatan mengenai aktivitas pengunjung sehari-hari di Blok $M$, The Third place sebagai variabel bebas yang berhubungan langsung dengan variabel tetap, dan pertunjukan seni sebagai variabel bebas kedua yang menjembatani hubungan antara para pengunjung Blok $M$ dan The Third place. 


\section{Tujuan Dan Manfaat Penelitian}

Tujuan penelitian ini untuk merancang proyek yang dapat mewadahi kegiatan seni komunitas-komunitas dan juga sebagai tempat masyarakat sekitar untuk berkumpul dan berinteraksi. Proyek ini juga ditujukan agar dapat menghidupkan kembali kawasan Blok M khususnya Melawai sehingga masyarakat diluar kawasan Blok $M$ tertarik untuk datang dan dapat memperluas jaringan interaksi antara masyarakat sekitar.

\section{KAJIAN LITERATUR}

Kajian literatur membahas tentang teori-teori yang berhubungan dengan konsep proyek yang akan dibangun, seperti teori dari Ray Oldenburg yang membahas karakteristik dari The Third place dan Richard Florida yang membahas tentang generasi dan karakteristik orangorang kreatif.

\section{Ray Oldenburg "the great,good,place"}

Ray Oldenburg dalam bukunya yang berjudul "The Great Good Place" mengatakan bahwa The Third place merupakan tempat ketiga yang dibutuhkan oleh masyarakat selain First Place (Tempat Tinggal) dan Second Place (Tempat Kerja). The Third place juga merupakan sebuah tempat informal yang dijadikan sebagai tempat untuk berkumpul,berinteraksi,dan bersosialisasi antara sesama manusia dengan tujuan agar manusia dapat menjadi pribadi yang lebih humanis dan peduli terhadap sesamanya.

\section{Richard Florida}

Pada buku ini, setidaknya ada Tiga hal penting atau kuncinya, yaitu Kreatifitas adalah sumber dari pertumbuhan ekonomi, Kreatifitas datang dari manusia, dan tempat merupakan hal yang esensial untuk mengembangkan Kreatifitas. Semua orang adalah orang yang kreatif, tantangan sebuah negara atau bangsa adalah mengeluarkan dan mengembangkan energi kreatitifas, talenta, dan potensi itu dari semua orang, agar dapat membangun masyarakat dan negara yang berkembang, menerima, dan menyadari akan pentingnya keberagaman setiap manusia.
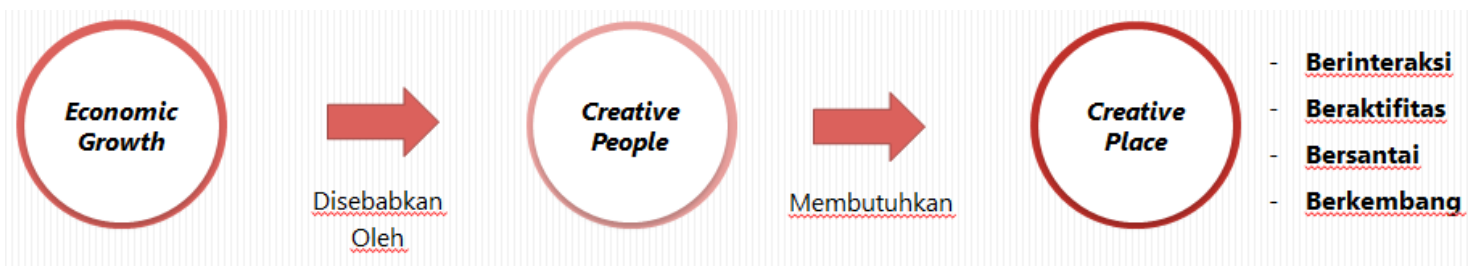

Gambar 1. Diagram Creative Place Sumber: Penulis, 2019

\section{METODE PENELITIAN}

Berikut merupakan diagram urutan metode yang digunakan untuk penelitian dan hasil pengamatan di lapangan, berikut merupakan diagram persentase aktivitas-aktivitas yang terjadi di area Blok M dari Pagi hingga Malam hari dan Mapping kegiatan yang terdapat di Blok M. 


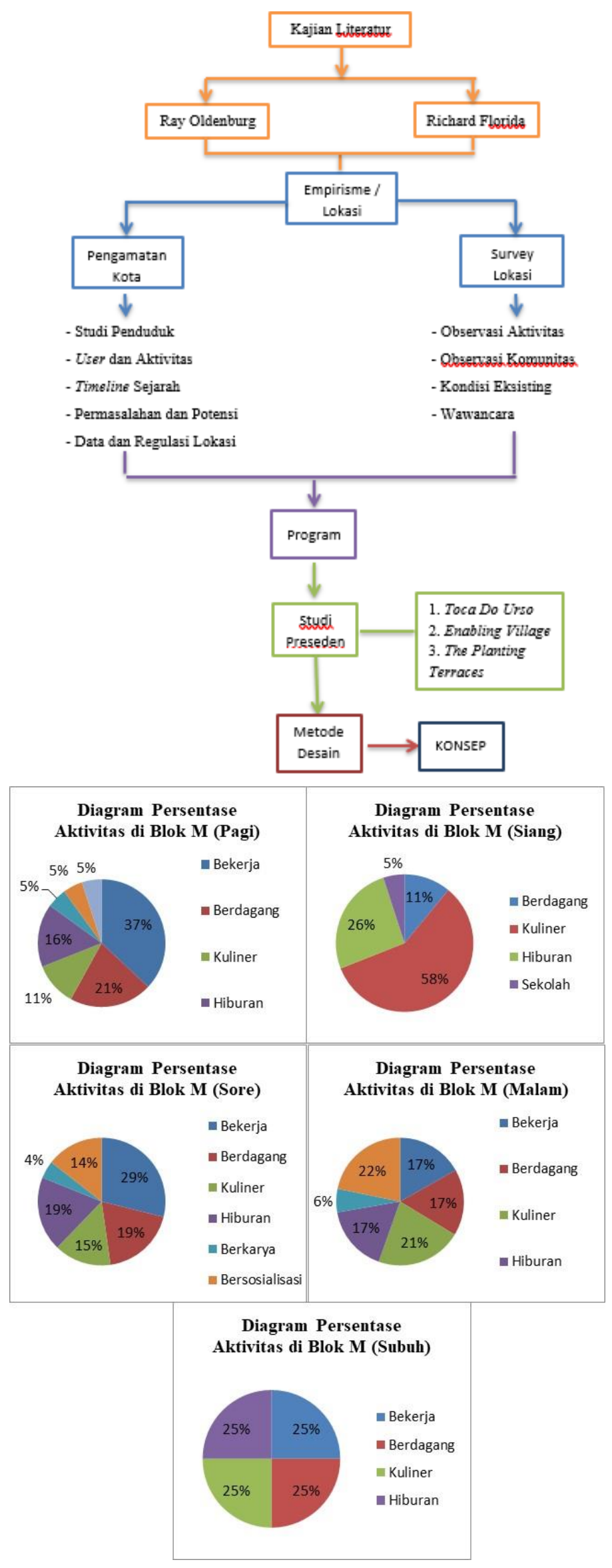

Gambar 2. Diagram Persentase Aktivitas di Blok M

Sumber: Penulis, 2019 
Dari data di atas, dapat disimpulkan bahwa Blok M didominasi oleh kegiatan berdagang, bekerja, kuliner, serta hiburan. Blok $\mathrm{M}$ merupakan kawasan perdagangan dan juga dikenal dengan berbagai kuliner yang murah dan unik seperti Gultik Blok M, makanan khas Jepang dan yang lainnya. Berikut terdapat Mapping dari aktivitas-aktivitas yang ada di Blok $\mathrm{M}$ :
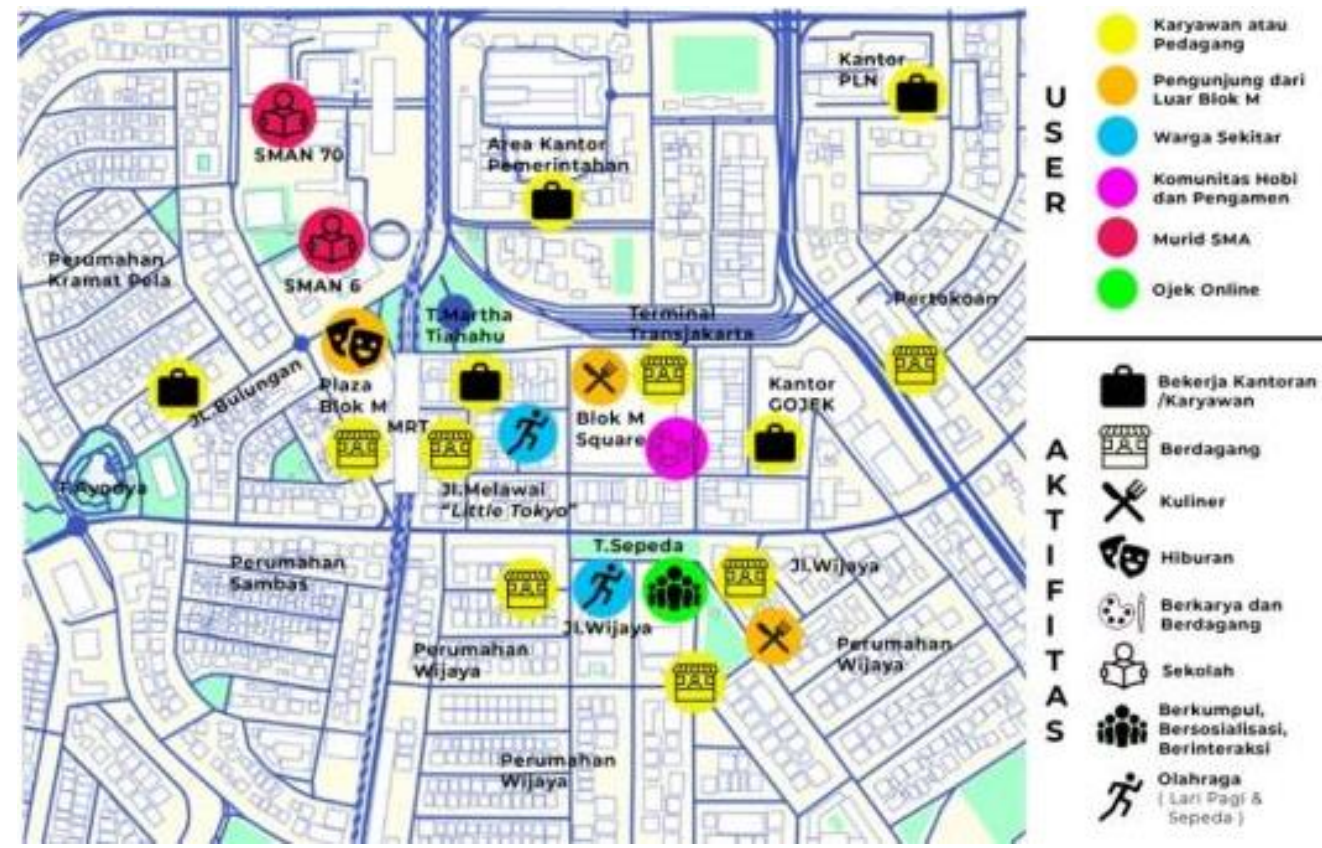

Gambar 3. Mapping Aktivitas di Blok M Waktu Pagi Sumber: Penulis, 2019
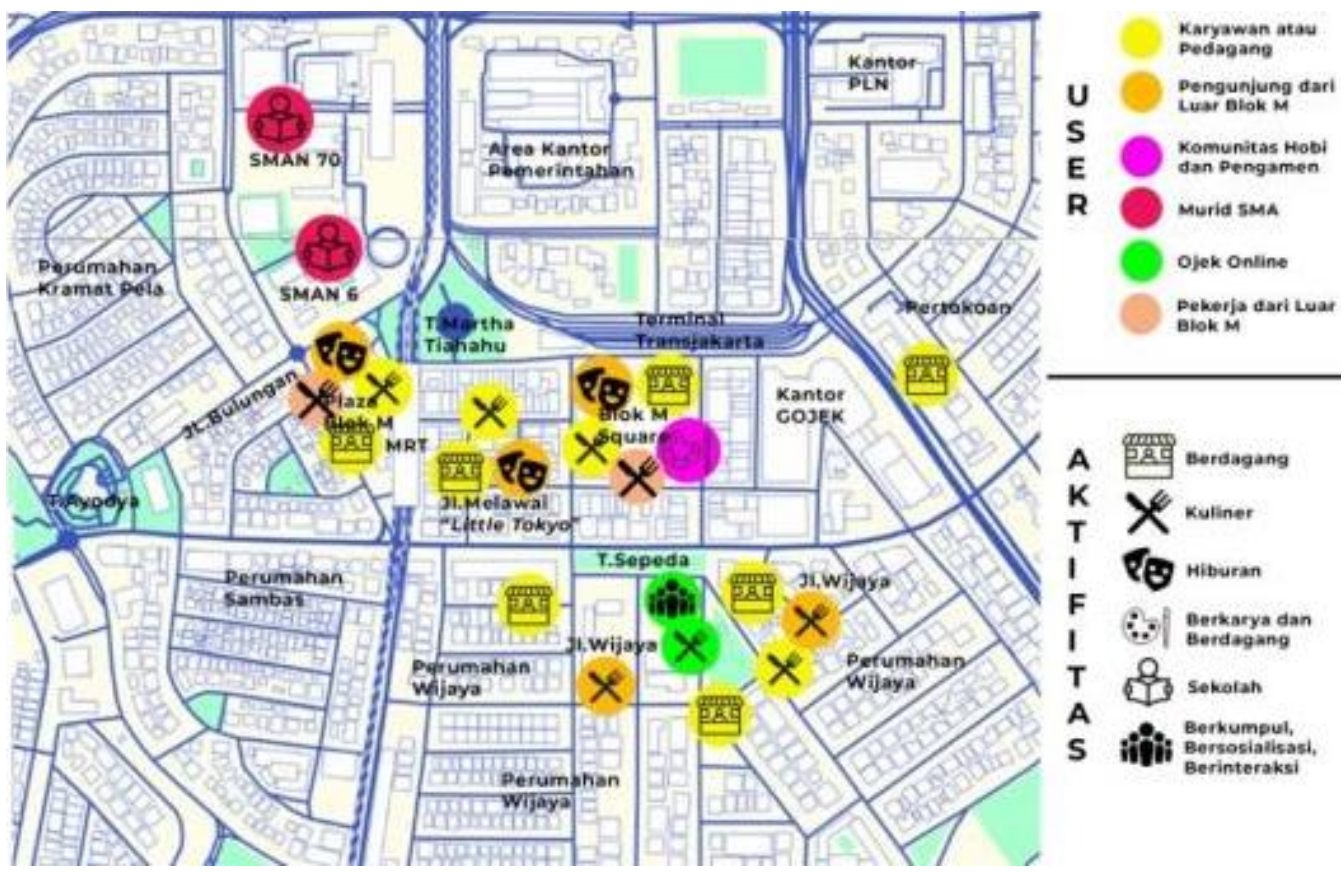

Gambar 4. Mapping Aktivitas di Blok M Waktu Siang

Sumber: Penulis, 2019 


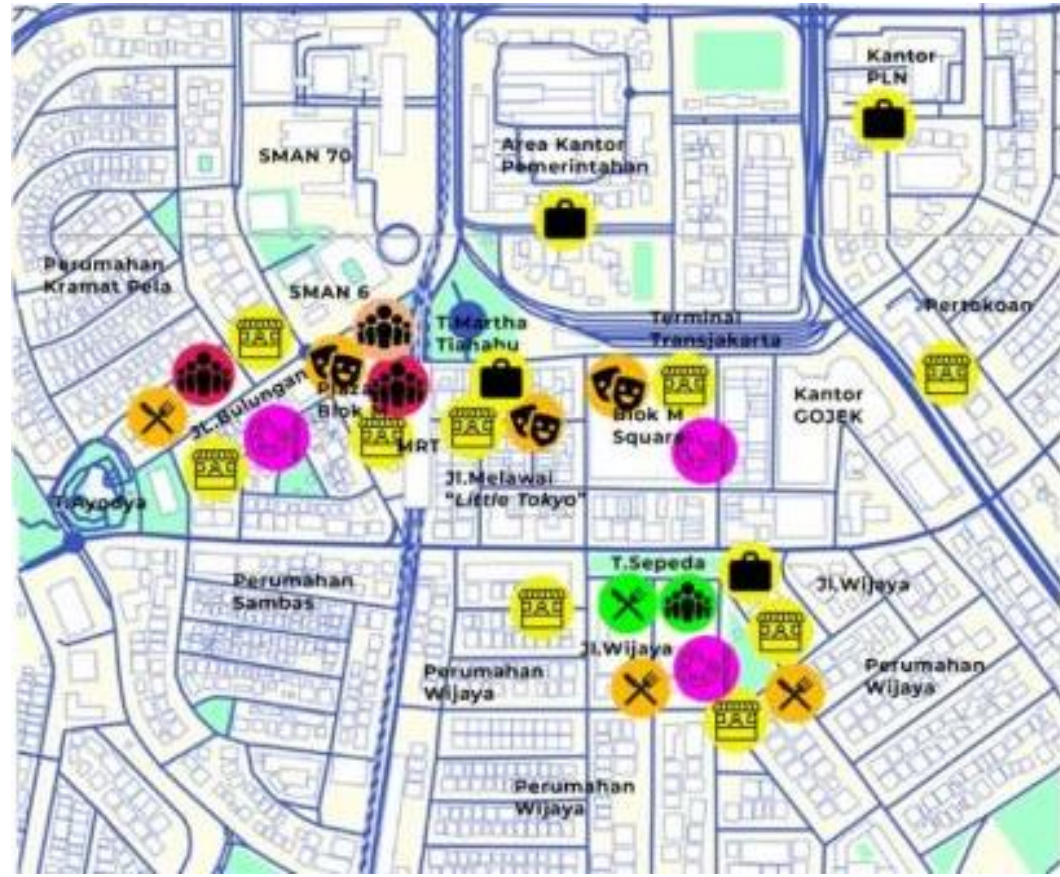

Gambar 5. Mapping Aktivitas di Blok M Waktu Sore Sumber: Penulis, 2019

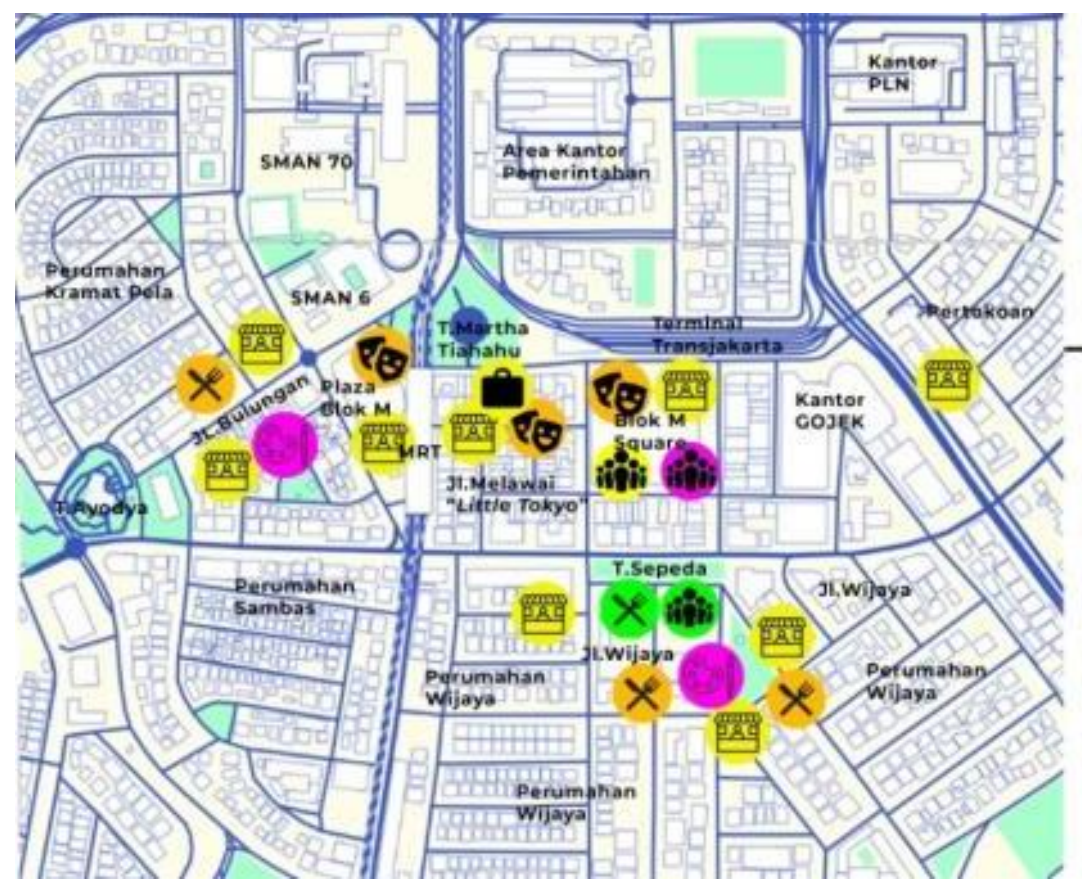

Gambar 6. Mapping Aktivitas di Blok M Waktu Malam Sumber: Penulis, 2019

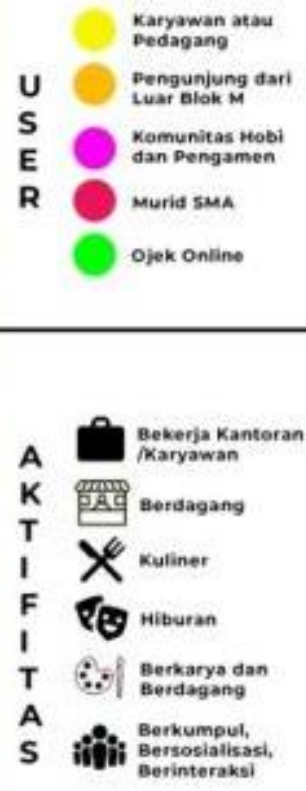
pedagang

dari

Murid sma

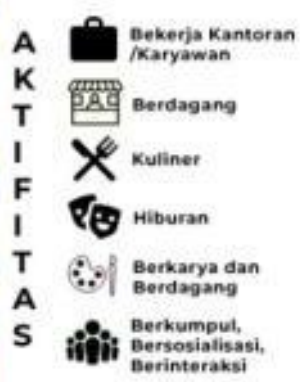




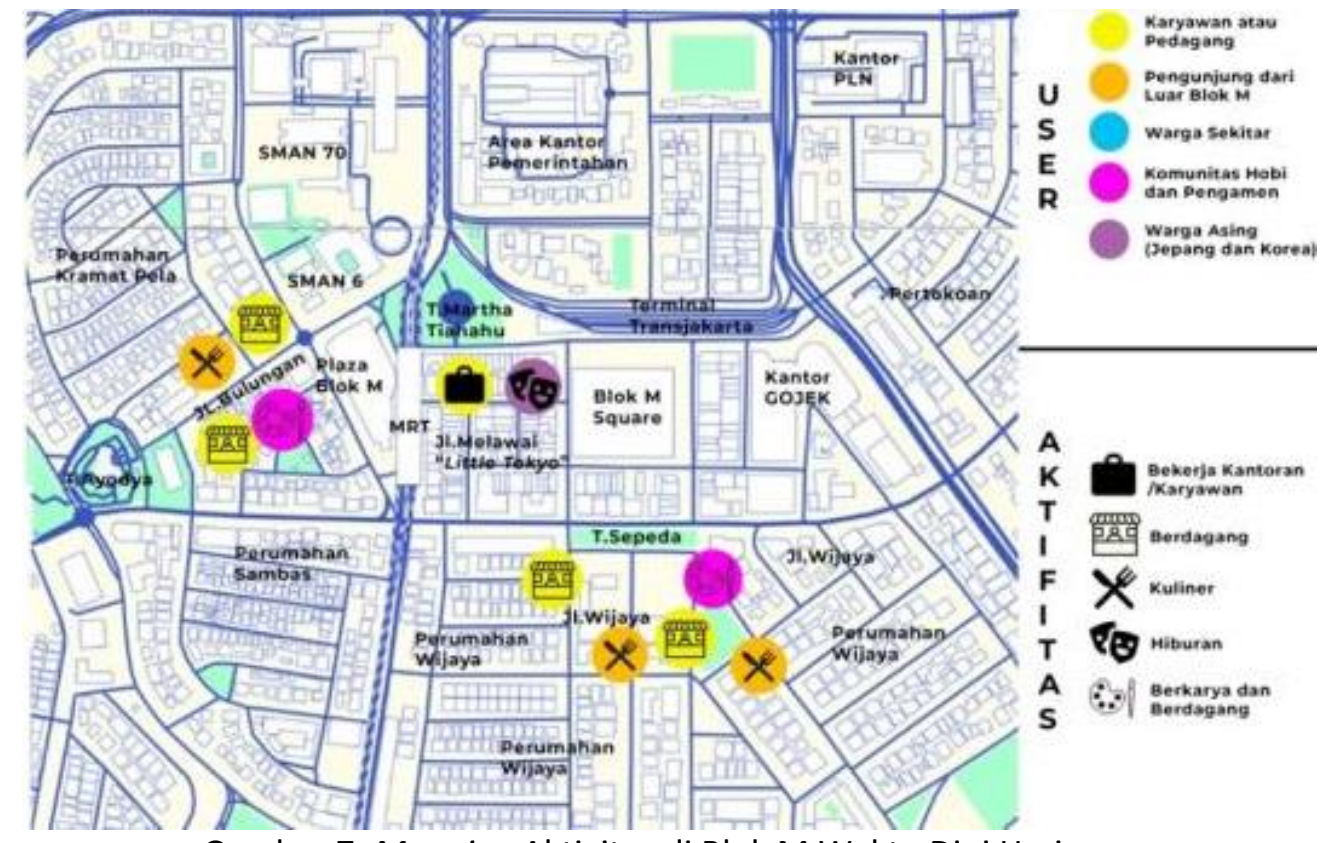

Gambar 7. Mapping Aktivitas di Blok M Waktu Dini Hari

Sumber: Penulis, 2019

Dari gambar mapping di atas, dapat disimpulkan bahwa Blok M merupakan kawasan yang hidup selama 24 jam. Dimana ketika Pagi hari didominasi oleh kegiatan olahraga dan kuliner, Siang hari didominasi oleh kegiatan perkantoran dan perdagangan, Sore hari didominasi oleh kegiatan komunitas atau sosialisasi dan malam hari hingga dini hari didominasi oleh kegiatan dunia malam seperti bar, karaoke dan lain-lain.

\section{DISKUSI DAN HASIL}

\section{Hasil Kajian}

Berdasarkan dari kajian teori oleh Richard Florida dan Ray Oldenburg, dimana sebuah tempat dapat dikatakan sebagai Third place jika mengusung konsep yang dapat membuat masyarakat dapat saling berinteraksi dan merasa nyaman dan juga berdasarkan Richard Florida yaitu orang-orang kreatif yang memerlukan aktivitas-aktivitas pelepas penat yang kreatif. Sehingga proyek ini dibuat dengan desain konsep bangunan yang terbuka atau welcoming sehingga masyarakat dari berbagai kalangan tertarik untuk datang ke proyek. Dibuat juga berbagai ruang terbuka maupun tertutup dimana komunitas-komunitas dapat berkumpul, berinteraksi dan juga mempertunjukan karya-karya kreatif mereka ke masyarakat luas yang akan membawa dampak positif dan ide-ide baru bagi masyarakat.

\section{Konsep Proyek}

Melalui analisa tapak sekitar dan aktivitas, dimana banyak sekali komunitas-komunitas seni yang mulai kehilangan tempat untuk berkarya dan berkumpul. Proyek ini memiliki konsep pertunjukan seni yang diadakan oleh komunitas-komunitas setempat dan juga diharapkan komunitas-komunitas tersebut dapat berkolaborasi untuk memunculkan pertunjukan seni yang baru dan unik. Blok $\mathrm{M}$ dikenal dengan banyaknya komunitas yang bermacam-macam mulai dari komunitas tradisional sampai komunitas kontemporer seperti contohnya komunitas Betawi, komunitas Jepang dan lain-lain. Maka dari itu, desain dirancang dengan konsep kontemporer yang dikolaborasikan dengan elemen-elemen tradisional, sehingga nyaman dan menarik bagi berbagai kalangan mulai dari kalangan millenials sampai kalangan lainnya. Program disesuaikan dengan aktivitas-aktivitas yang biasa dilakukan di sekitar kawasan dan juga dari kebutuhan,serta luasan didasarkan oleh analisa-analisa data tapak sekitar, mulai dari aktivitas sehari- hari pengunjung atau masyarakat sekitar dan juga loci kawasan. Program program proyek antara lain : 

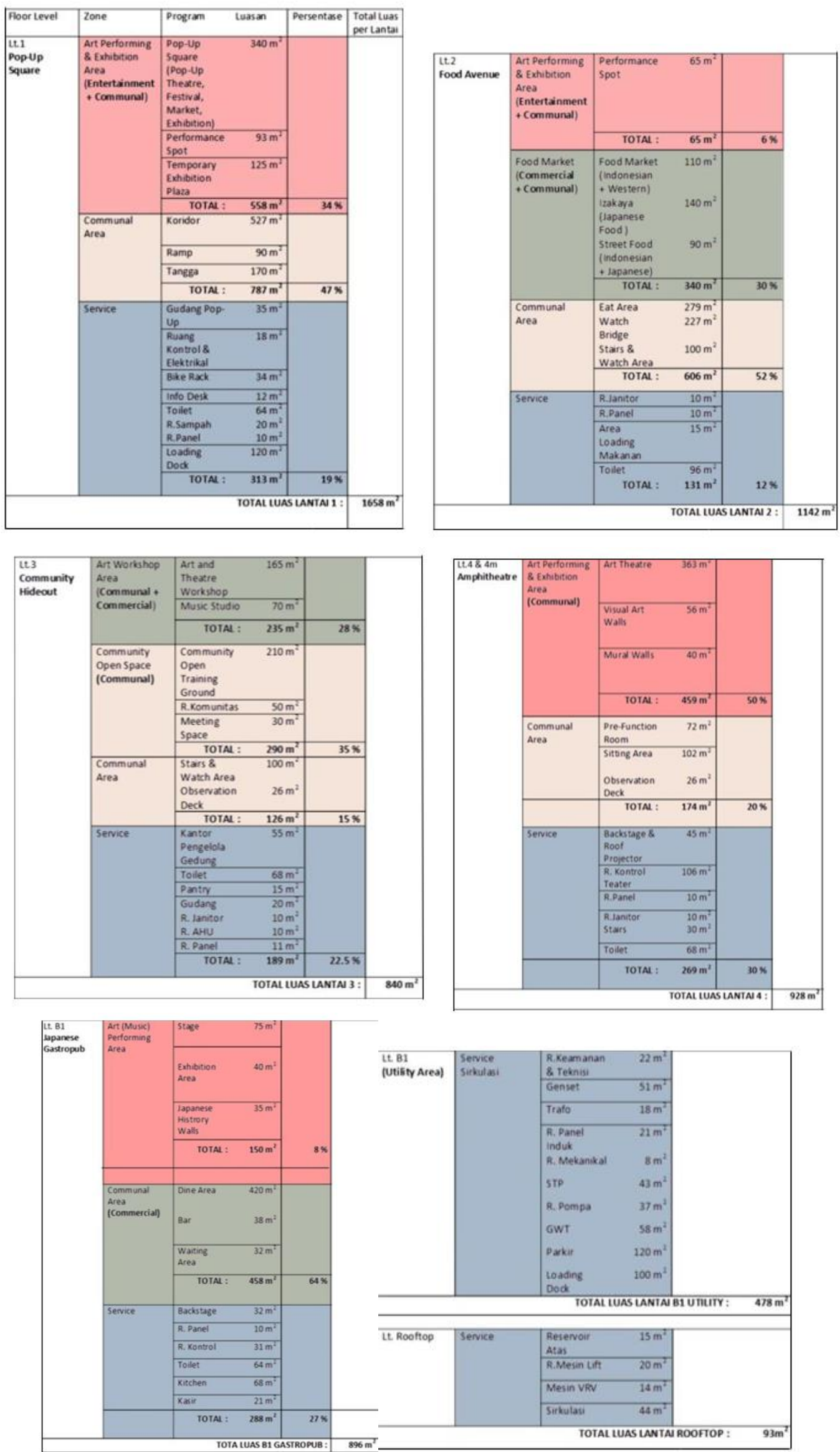

Gambar 8. Tabel Program

Sumber : Dokumen Pribadi, 2019 
Tapak berada di Jl. Melawai 9, Blok M, Kebayoran Baru, Jakarta Selatan. Tapak ini memiliki beberapa keunggulan seperti dekat dengan Moda Raya Terpadu (MRT), pusat aktivitas masyarakat dan juga keunikan kawasan itu sendiri. Proyek terancang memiliki KDB $2068 \mathrm{~m}^{2}$, KLB $6035 \mathrm{~m}^{2}, \mathrm{KDH} 1178 \mathrm{~m}^{2}$, KTB $1533 \mathrm{~m}^{2}$ dan tinggi bangunan 4 lantai.

\section{KESIMPULAN DAN SARAN}

Proyek Ruang Pertunjukan Seni merupakan ruang yang mewadahi komunitas-komunitas seni setempat yang terdapat berbagai kategori dari budaya, musik, tari dan dibagi lagi menjadi tradisional dan kontemporer. Komunitas-komunitas tersebut kemudian dapat mempertunjukan karya-karya mereka ke masyarakat luas sehingga ada proses timbal balik yang terjadi atau sebuah interaksi yang mengacu pada konsep Third place, dimana masyarakat dapat saling berkumpul dan berinteraksi dengan sesama.

Kemudian juga proyek ini tidak menutup kemungkinan untuk menghasilkan sebuah kolaborasi pertunjukan seni yang baru karena proyek ini memang berfungsi sebagai tempat berkumpulnya para komunitas dari berbagai macam jenis. Dari analisa-analisa kawasan dan aktivitas masyarakat, proyek ini memiliki berbagai program seperti Japanese Gastropub dikarenakan Melawai ketika malam hari terdapat beberapa tempat bar, restoran dan lain-lain yang bertemakan Jepang, kemudian dilanjut dengan Pop-Up Square yang merupakan tempat dapat digunakan untuk masyarakat bersantai, berkumpul, melihat pertunjukan seni dan juga dapat dijadikan tempat untuk pentas seni. Selain itu, terdapat area makan, area berkumpulnya komunitas-komunitas lengkap dengan tempat berlatih atau workshop area dan juga sebuah Teater.

Semua ini dibungkus dalam sebuah bangunan yang didesain secara kontemporer dengan campuran tradisional pada interiornya untuk dapat lebih mengundang berbagai jenis umur masyarakat. Diharapkan juga proyek ini dapat menjadi pemicu perkembangan kawasan Blok $\mathrm{M}$ dan juga menjadi tempat yang nyaman dan aman bagi masyarakat untuk berkumpul dan berinteraksi.

\section{REFERENSI}

Florida, R. (2012). The Rise Of The Creative Class. New York: Basic Books Montgomerry, C. (2013). Happy City. Canada: Farrar

Oldenburg, R. (1997). The Great, Good Place. Cambridge: Da Capro Press

Soja, E. (1996). Thirdspace: Journeys to Los Angeles and Other Real-and-Imagined Places.

Cambridge

Tuan, Y.(1977). Space and Place. Minneapolis: University of Minnesota 
